\title{
A CERTIFICAÇÃO DE ADQUIRIDOS EXPERIENCIAIS E SUAS CONSEQUÊNCIAS NAS TRAJECTÓRIAS DE VIDA: O CASO DO ALENTEJO, NO PERÍODO 2000-2005
}

\author{
Bravo Nico, Lurdes Pratas Nico, Fátima Ferreira, Antónia Tobias \\ Centro de Investigação em Educação e Psicologia \\ Universidade de Évora
}

\section{Introdução}

Entre 2000 e 2005, na região Alentejo, um total de 2969 adultos viram certificadas as competências adquiridas por via da experiência de vida e profissional, através da realização de um processo de Reconhecimento, Validação e Certificação de Competências, alterando, dessa forma as respectivas habilitações académicas.

Naquele período, o processo era concretizado numa rede de Centros de RVCC promovida por 6 instituições: Fundação Alentejo/Évora; ESDIME/Messejana, Centro de Formação Profissional de Portalegre do Instituto do Emprego e Formação Profissional; Associação de Desenvolvimento do Litoral Alentejano/Santiago do Cacém; Rota do Guadiana/Serpa e Terras Dentro/Viana do Alentejo que, na época, constituíam a rede a operar no território daquela região do sul de Portugal.

Esta população (2969 indivíduos) foi submetida a um inquérito que assumiu, como objectivo, a avaliação de eventuais impactos da frequência deste percurso de qualificação e da obtenção da respectiva certificação, nas diferentes dimensões dos indivíduos: pessoal, profissional, social e continuação de trajectórias formativas.

Os resultados que se apresentam de seguida, foram resultado de um projecto de investigação promovido pelo Departamento de Pedagogia e Educação da Universidade de Évora e financiado pela Fundação para a Ciência, denominado "As Novas Núpcias da Qualificação no Alentejo". Este projecto concretizou-se entre Junho de 2010 e Maio de 2013.

Esta comunicação encontra-se estruturada em 4 partes: (i) a caracterização da rede de Centros de RVCC, entre 2000 e 2005; (ii) a descrição do desenho da investigação; (iii) a apresentação de alguns resultados da investigação. Esta terceira, e 
última parte, encontra-se subdividida em 3 pontos: (a) caracterização dos indivíduos participantes no estudo; (b) caracterização do Processo de RVCC concretizado pelos inquiridos; (c) avaliação de alguns dos impactos do Processo de RVCC nos adultos certificados.

\section{A rede de Centros de Reconhecimento, Validação e Certificação no Alentejo (2000-2005)}

Através da publicação da Portaria n. 1082-A/2001, de 5 de Setembro foi criada uma Rede Nacional de Centros de Reconhecimento, Validação e Certificação de Competências (Centros de RVCC), a partir da qual se promoveu o Sistema de Reconhecimento, Validação e Certificação de Competências.

O Sistema Nacional de RVCC concretizou-se, assim, numa rede de centros articulados entre si. Esta rede foi, desde Novembro de 2000, constituída numa fase experimental, por 6 Centros-piloto (centros em observação), em todo o contexto nacional. Na região Alentejo, a ESDIME foi uma das entidades piloto, no âmbito dos Centros de RVCC, em 2000. Um dos critérios de selecção foi a experiência adquirida no âmbito destes Cursos EFA (ESDIME, 2007).

Tabela 1 - Rede inicial de Centros de RVCC na Região Alentejo (2000-2005)

\begin{tabular}{|l|c|c|c|}
\hline Designação do Centro de RVCC & Localização & Ano de Criação & Tipologia da entidade \\
\hline $\begin{array}{l}\text { ESDIME - Agência para o } \\
\text { Desenvolvimento Local do } \\
\text { Alentejo e Sudoeste, Lda. }\end{array}$ & $\begin{array}{l}\text { Messejana } \\
\text { (Aljustrel) }\end{array}$ & 2000 & Privada \\
\hline Fundação Alentejo & Évora & 2001 & Privada \\
\hline $\begin{array}{l}\text { Centro de Formação } \\
\text { Profissional de Portalegre } \\
\text { (IEFP) }\end{array}$ & Portalegre & 2001 & Pública (IEFP Gestão Directa) \\
\hline $\begin{array}{l}\text { ADL - Associação para o } \\
\text { Desenvolvimento do Litoral } \\
\text { Alentejano }\end{array}$ & $\begin{array}{c}\text { Santiago do } \\
\text { Cacém * }\end{array}$ & 2003 & Privada \\
\hline $\begin{array}{l}\text { Rota do Guadiana - Associação } \\
\text { de Desenvolvimento Integrado }\end{array}$ & Serpa & 2004 & \\
\hline
\end{tabular}

\footnotetext{
${ }^{1}$ O Centro de RVCC localizava-se no concelho de Ferreira do Alentejo (Casa do S@ber+)
} 


\begin{tabular}{|l|l|l|l|}
\hline $\begin{array}{l}\text { Terras Dentro - Associação } \\
\text { para o Desenvolvimento } \\
\text { Integrado }\end{array}$ & $\begin{array}{l}\text { Alcáçovas } \\
\text { (Viana do } \\
\text { Alentejo) }\end{array}$ & 2005 & Privada \\
\hline
\end{tabular}

Fonte: NICO, L. (2009:264)

Nos Centros de RVCC, os adultos viram reconhecidas as competências adquiridas através da experiência de vida e, partindo desse processo, obtiveram a certificação escolar equivalente ao Nível Básico (1.ำ 2.ำ 3.ำ Ciclos) e, em momento posterior (2007), o Nível Secundário (12.ำ ano).

Nos seis Centros de RVCC, na região Alentejo, no período 2000-2005, conforme foi referido, foram certificados um total de 2969 indivíduos, distribuídos por ano e nível de certificação, conforme se apresenta na Tabela 2.

Tabela 2 - Execução Física dos Centros de RVCC

(adultos certificados entre 2001 e 2005, por nível de certificação)

\begin{tabular}{|c|c|c|c|}
\hline \multirow{2}{*}{ Ano } & \multicolumn{3}{|c|}{ Nível de certificação } \\
\cline { 2 - 4 } & B1 & B2 & B3 \\
\cline { 2 - 4 } & $\begin{array}{c}\text { (1.o Ciclo do } \\
\text { Ensino Básico) }\end{array}$ & $\begin{array}{c}\text { (2.o Ciclo do } \\
\text { Ensino Básico) }\end{array}$ & $\begin{array}{c}\text { (3.o Ciclo do } \\
\text { Ensino Básico) }\end{array}$ \\
\hline 2001 & 0 & 1 & 25 \\
\hline 2002 & 1 & 29 & 282 \\
\hline 2003 & 2 & 46 & 703 \\
\hline 2004 & 6 & 75 & 795 \\
\hline 2005 & 3 & 58 & 943 \\
\hline Subtotal & 12 & $\mathbf{2 0 9}$ & $\mathbf{2 7 4 8}$ \\
\hline Total & & $\mathbf{2 9 6 9}$ & \\
\hline Fonte: NICO (2009:275) & & & \\
\hline
\end{tabular}

Da leitura do quadro anterior, pode concluir-se que:

- Entre 2001 e 2005, na Região do Alentejo, foram certificados 2969 adultos, dos quais 2748 (92,6\%) obtiveram o 3. Ciclo do Ensino Básico (Nível B3 - 9.ำ ano), 209 (7,0 \%) adultos o 2. Ciclo do Ensino Básico (Nível B2 - 6. ano) e 12 adultos (0,4\%) com o 1.ํ Ciclo do Ensino Básico (Nível B1 - 4. ano);

- Por ano civil, foi em 2005 que se verificou um maior número de adultos que concluíram, com sucesso, o processo de RVCC;

- Ao nível de certificação, B1 e B2, o maior n.ำ de adultos certificados registou-se em 2004; já no Nível B3, o maior n.o de adultos certificados ocorreu no ano 2005; 
- Podemos inferir que, nos Centros que participam no estudo, os adultos que apresentam níveis de habilitação mais baixos, não procuram tanto os CRVCC para obter a qualificação, tendo em conta que, no Nível B1 (1.ํ Ciclo), se apresentam valores, que diríamos, quase residuais, face aos restantes dados obtidos.

Podemos ainda referir que, entre 2001 e 2005, no que respeita ao género, de acordo com os dados disponibilizados pelos Centros, $60 \%$ dos adultos certificados (1753) pelo Processo de RVCC são mulheres e 40\% são homens (1180) (Nico, 2009:276).

O processo de RVCC era desenvolvido tendo por base o Referencial de Competências-Chave, de básico e concretizado em 3 eixos fundamentais: o eixo do reconhecimento, o eixo da validação e o eixo da certificação. Na janela temporal do nosso estudo (2000-2005) apenas existia o Referencial de Competências-Chave de Nível Básico (Alonso, Imaginário \& Magalhães, 2001). O Referencial de CompetênciasChave de nível secundário viria a ser apresentado em 2006.

A realização de um processo de RVCC, nomeadamente a partir do processo de Balanço de Competências, implica, por parte do adulto, a construção do Dossier Pessoal (mais tarde, no nível secundário, designado de Portefólio Reflexivo de Aprendizagens).

Apresentamos, de seguida, o percurso que um adulto percorria, desde a sua inscrição no Centro de RVCC até à certificação (Figura 1).

Figura 1 - Etapas de intervenção do Centro de RVCC 


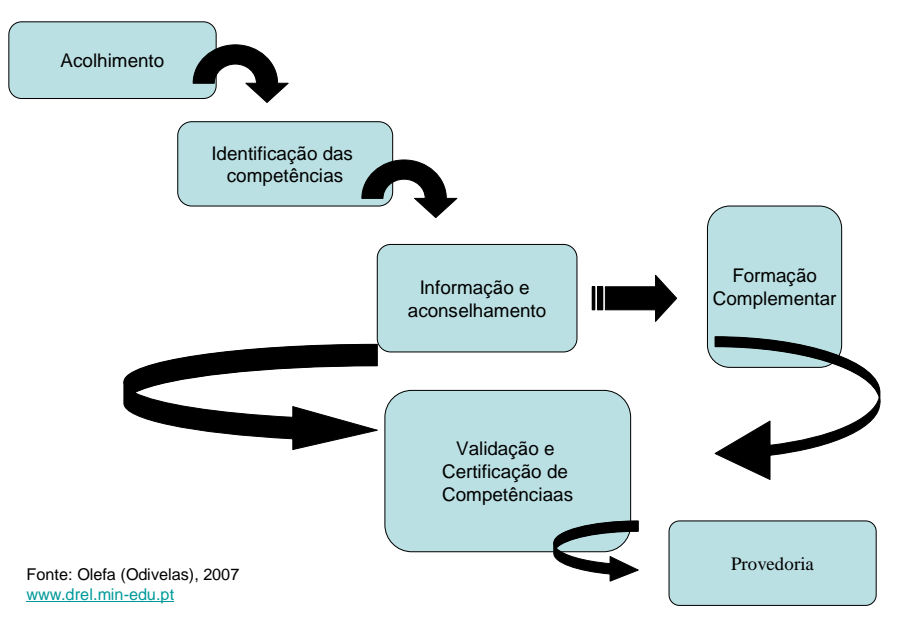

Os Centros de Reconhecimento, Validação e Certificação de Competências (CRVCC) são, desde o início de 2006, sujeitos a profundas alterações de natureza legal e ao nível organizacional e de gestão, pois os seus objectivos e funções são alterados para que possam estar em conformidade com os princípios preconizados na Iniciativa Novas Oportunidades, no que à população adulta diz respeito, sob a tutela da Agência Nacional para a Qualificação, I.P.

Os Centros de RVCC passam a designar-se Centros Novas Oportunidades (CNO), integram novos elementos, o processo de RVCC é alargado ao nível secundário de educação e aumenta o número de Centros a funcionar, em todo o país (Portaria n.o 370/2008, de 21 de Maio). O Sistema de RVCC, em 2010, era concretizado numa rede de 453 Centros Novas Oportunidades disseminados por todo o país, 40 dos quais na região Alentejo. ${ }^{2}$

Actualmente, o instituto que, a nível central tem a missão de coordenar a rede de Centros Novas Oportunidades e o sistema de RVCC é a Agência Nacional para a Qualificação e o Ensino Profissional (ANQEP, I.P.).

A rede de Centros Novas Oportunidades foi extinta em 31 de Março de 2013, sendo criados os Centros para a Qualificação e o Ensino Profissional (CQEP), em substituição dos Centros Novas Oportunidades, através da publicação da Portaria n.o

\footnotetext{
${ }^{2}$ www.novasoportunidades.gov.pt
} 
135-A/2013 de 28 de Março, que regula a criação e o regime de organização e funcionamento dos CQEP.

\section{Desenho da investigação}

O desenho da investigação recorreu a uma abordagem de matriz essencialmente quantitativa, com o recurso à construção (concepção e validação) e aplicação de um inquérito por questionário, baseado em instrumento anteriormente desenvolvido por Nico (2009), de acordo com o procedimento formulado por Punch (1998), Hill \& Hill (2005) e Leinhardt \& Leinhardt (1990).

A análise da informação recolhida foi feita através da utilização da plataforma estatística construída para o efeito, em suporte SPSS (Statistical Package for the Social Sciences).

A abordagem privilegiada assentou numa matriz descritiva (Tabela 3). Contudo, no sentido de se avaliarem diferenças, em determinadas variáveis consideradas dependentes em função de outras variáveis assumidas como independentes e dada a natureza dos dados, recorreu-se, ao longo do estudo, ao Método de Monte-Carlo na determinação da significância do Qui-Quadrado (Chisquare test), ignorando os resultados assimptóticos do teste.

Tabela 3 - Procedimento geral da investigação

\begin{tabular}{|c|l|l|}
\hline & \multicolumn{1}{|c|}{ Abordagem qualitativa } & \multicolumn{1}{c|}{ Referências Bibliográficas } \\
\hline $\begin{array}{c}\text { População } \\
\text { Considerada }\end{array}$ & $\begin{array}{l}\text { Indivíduos adultos certificados nos Centros } \\
\text { RVCC, no Alentejo, no período 2001-2005 } \\
\text { (2969 indivíduos) }\end{array}$ & (1) Sousa (2005:70); \\
\hline $\begin{array}{c}\text { Fontes de } \\
\text { Informação }\end{array}$ & $\begin{array}{l}\text { - Bases de dados dos Centros de RVCC em (2005:49) } \\
\text { actividade no período 2001-2005 } \\
\text { - Conteúdo dos Inquéritos respondidos } \\
\text { pelos adultos certificados nos Centros } \\
\text { RVCC, no Alentejo, no ano 2003 (785) }\end{array}$ & \\
\hline $\begin{array}{c}\text { Instrumento } \\
\text { escolhido para a } \\
\text { recolha de } \\
\text { informação }\end{array}$ & - Inquérito por questionário (3) & (3) Sousa (2005:153); \\
\hline $\begin{array}{c}\text { Técnica de análise } \\
\text { da informação }\end{array}$ & $\begin{array}{l}\text { - Análise estatística descritiva e inferencial, } \\
\text { com recurso a plataforma estatística em } \\
\text { suporte SPSS (Statistical Package for the }\end{array}$ & $\begin{array}{l}\text { (4) Pereira (2008) } \\
\text { Shiglione \& Matalon (1992) }\end{array}$ \\
\hline
\end{tabular}




\section{Alguns resultados da investigação}

\subsection{Caracterização dos indivíduos participantes no estudo}

De um total de 2969 adultos certificados, entre 2000 e 2005, foram recebidos 785

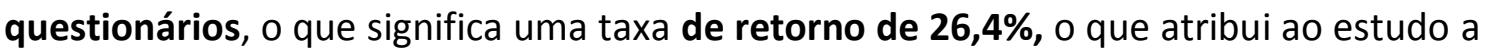
margem de erro de 3\%, para um nível de confiança de 95\% (Reis, Vicente \& Ferrão, 2001).

\section{- Origem institucional dos inquiridos}

A distribuição do número de questionários, por CRVCC, foi a seguinte:

Figura 2 - Inquiridos: origem institucional (totalidade dos inquiridos)

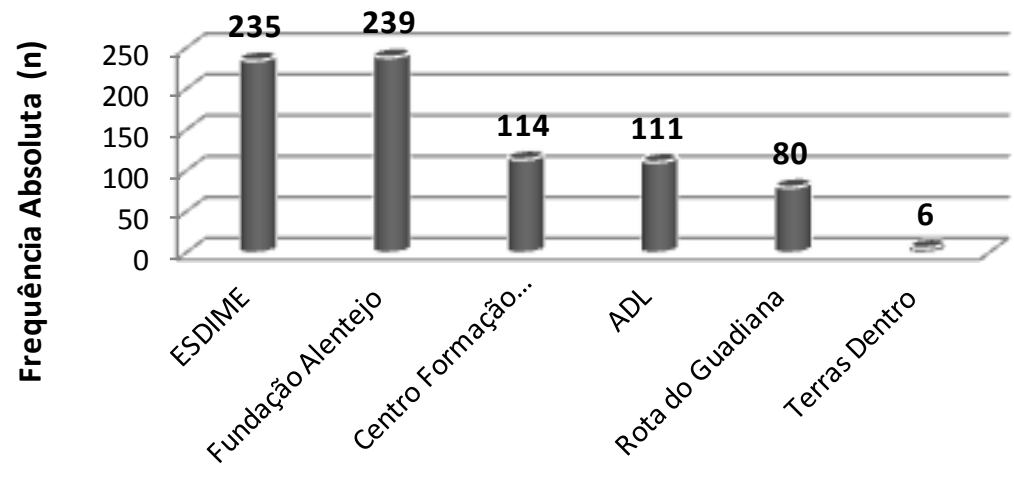

Centros de RVCC

Fonte: Inquérito por Questionário das Novas Qualificações, 2013

- Género dos inquiridos

Dos 785 adultos respondentes, mais de metade pertence ao género feminino (58\% do total), conforme se pode verificar, pela análise da Tabela 4.

Tabela 4 - Inquiridos: género (totalidade dos inquiridos) 


\begin{tabular}{|l|c|c|}
\hline \multicolumn{1}{|c|}{ Género } & $\begin{array}{c}\text { Frequência } \\
\text { Absoluta (n) }\end{array}$ & $\begin{array}{c}\text { Frequência } \\
\text { Relativa (\%) }\end{array}$ \\
\hline Masculino & 323 & 41,1 \\
\hline Feminino & 455 & 58 \\
\hline Sem resposta & 7 & 0,9 \\
\hline Totais & $\mathbf{7 8 5}$ & 100,0 \\
\hline
\end{tabular}

Fonte: Inquérito por Questionário das Novas Qualificações, 2013

O facto de a maioria dos adultos respondentes, nesta investigação, pertencer ao género feminino é uma evidência também presente em estudos anteriormente realizados, no âmbito da avaliação dos impactos do Processo de RVCC, na região Alentejo (Nico, 2009; Rico \& Libório, 2009).

\section{- Idade dos inquiridos}

No que respeita à idade, verificou-se um maior número de respondentes no grupo etário localizado entre os 41 e os 50 anos, correspondendo a $36,4 \%$ da amostra. Os grupos etários situados nos extremos (21-30 e 61-70 anos) apresentaram um menor número de respostas, conforme se pode observar na Figura 3:

Figura 3 - Inquiridos: idade (totalidade dos inquiridos)

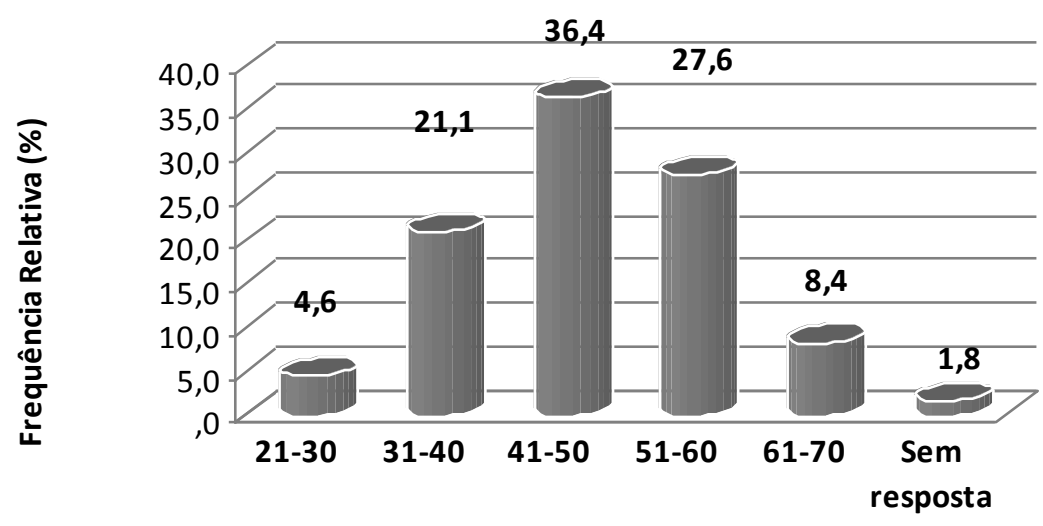

Grupos Etários

Fonte: Inquérito por Questionário das Novas Qualificações, 2013 
Da leitura da figura anterior, verifica-se que a maioria dos inquiridos (64\%) encontrava-se entre os 41 e os 60 anos (36, 4\%, entre os 41 e os 50 anos, e $27,6 \%$ entre os 51 e os 60 anos). Neste sentido, pode concluir-se que os primeiros Processos de RVCC foram concretizados, maioritariamente, por indivíduos com mais de $\mathbf{3 0}$ anos de idade e com uma experiência de vida decorrente dessa dimensão etária.

- Distrito e Concelho de residência dos inquiridos

1. De entre os 4 distritos que compõem a Região Alentejo ${ }^{3}$, o distrito de residência com maior número de respondentes é o distrito de Beja, com uma frequência relativa de 41,0\%, a que correspondem 322 indivíduos, seguindo-se o distrito de Évora, com uma frequência relativa de 29,8\% (234 indivíduos).

a) Foram identificados $\mathbf{5 3}$ concelhos, dos quais se destacam $\mathbf{4 3}$, por pertencerem à região Alentejo. Considerando os 47 concelhos da Região Alentejo, conclui-se que há apenas 4 concelhos que não estão representados no estudo: 3 do distrito de Portalegre - Monforte, Gavião e Avis; 1 do distrito de Setúbal Alcácer do Sal. Foi o concelho de Évora que apresentou o maior número de respostas (119 pessoas que responderam ao inquérito, o que corresponde a $15,2 \%$ do total da amostra.

- Situação familiar (estado civil e número de filhos)

A maioria dos indivíduos encontrava-se casada, 69,3\%. Os indivíduos viúvos constituíam-se como a categoria menos numerosa, representando apenas $\mathbf{3 , 7 \%}$ do total. No que respeita ao número de filhos verificou-se que: (i) $\mathbf{8 3 , 4 \%}$ dos inquiridos tinha filhos (48,2\% possuía 2 filhos e 27,3\% tinha 1 filho; apenas 7,9\% indicou ter 3 filhos); (ii) 14, 1\% dos inquiridos não tinha filhos.

- Habilitações escolares dos inquiridos, aquando da resposta

\footnotetext{
${ }^{3}$ A região do Alentejo compreende cinco sub-regiões estatísticas (NUT III): Alentejo Central, Alentejo Litoral, Alto Alentejo, Baixo Alentejo e Lezíria do Tejo. Os dados apresentados não incluem a NUT III da Lezíria do Tejo, na medida em que se assume, no estudo, a zona de jurisdição da Comissão de Coordenação e Desenvolvimento Regional do Alentejo (CCDRA), à época (2000-2005). Esta circunscrevia-se a 47 concelhos distribuídos pelos distritos de Évora, Beja, Portalegre e uma parte do distrito de Setúbal (neste último, apenas os concelhos de Sines, Santiago do Cacém, Alcácer do Sal e Grândola).
} 
No que respeita às Habilitações Escolares dos inquiridos, a informação recolhida encontra-se na tabela seguinte.

Tabela 5 - Inquiridos: habilitações escolares aquando da resposta (totalidade dos inquiridos)

\begin{tabular}{|l|c|c|}
\hline Habilitações escolares & $\begin{array}{c}\text { Frequência } \\
\text { Absoluta } \\
\text { (n) }\end{array}$ & $\begin{array}{c}\text { Frequência } \\
\text { Relativa } \\
\text { (\%) }\end{array}$ \\
\hline 1ㅇ Ciclo & 9 & 1,1 \\
\hline 2o Ciclo & 46 & 5,9 \\
\hline 3o Ciclo & $\mathbf{4 3 3}$ & $\mathbf{5 5 , 2}$ \\
\hline Secundário & 259 & 33 \\
\hline $\begin{array}{l}\text { CET (Curso Especialização } \\
\text { Tecnológica) }\end{array}$ & 12 & 1,5 \\
\hline Bacharelato Totais & 1 & 0,1 \\
\hline Licenciatura & 13 & 1,7 \\
\hline Sem resposta & 12 & 1,5 \\
\hline \multicolumn{1}{|c|}{} & & $\mathbf{1 0 0 , 0}$ \\
\hline
\end{tabular}

Fonte: Inquérito por Questionário das Novas Qualificações, 2013

Da leitura da tabela anterior, verifica-se o seguinte:

a) 433 pessoas inquiridas (que correspondem a $\mathbf{5 5 , 2} \%$ da amostra) referiram ter 0 3 ciclo de escolaridade;

b) O segundo nível de escolaridade mais frequente foi o Ensino Secundário, referido por 259 inquiridos, o que representa 33,0\% da amostra considerada;

c) 13 dos inquiridos $(1,7 \%)$ referiram possuir, actualmente, uma Licenciatura;

d) $\mathbf{3 6 , 3}$ dos indivíduos que realizaram um Processo de RVCC de nível básico (o único existente no período considerado, 2000-2005) aumentou, entretanto, os seus níveis de escolaridade. Este facto evidencia o vigor do impulso de qualificação recebido pelos adultos e a dinâmica de aprendizagem que ficou instalada, após a conclusão do Processo RVCC.

A análise estatística complementar - entretanto realizada, com base nos testes referidos anteriormente referidos - revelou que: (i) os homens possuem níveis de escolaridade mais elevados do que as mulheres; (ii) os indivíduos mais jovens possuem níveis de escolaridade mais elevados do que os restantes. 
- Situação face aos estudos, aquando da resposta

No que se refere à situação face aos estudos, no momento da aplicação do questionário, a informação obtida foi organizada na figura seguinte:

Figura 4 - Inquiridos: Situação face aos estudos (totalidade dos inquiridos)

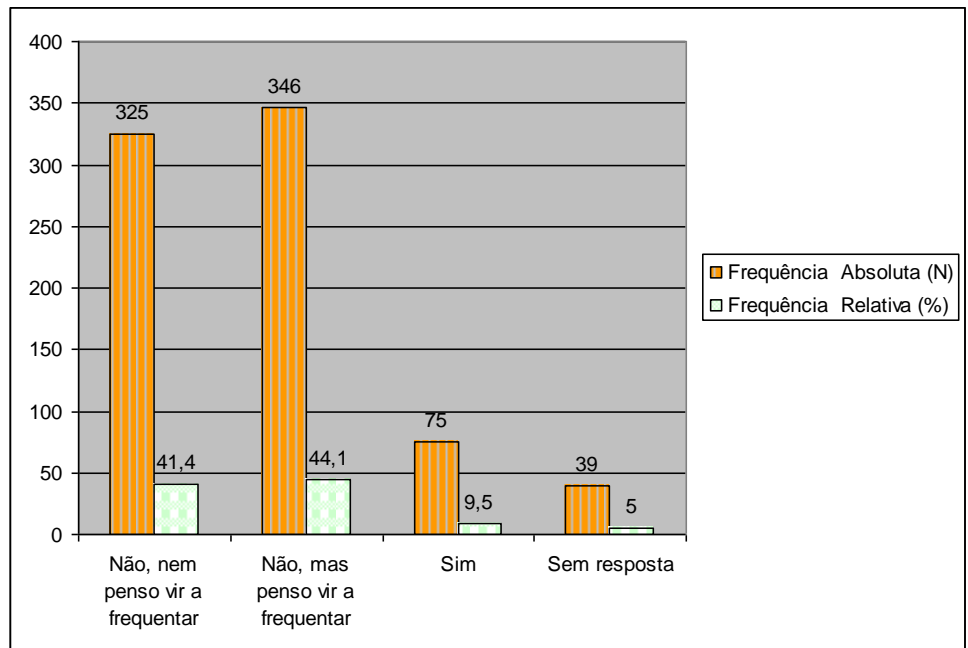

Fonte: Inquérito por Questionário das Novas Qualificações, 2013

Da leitura da tabela anterior, conclui-se o seguinte:

a) A grande maioria dos indivíduos $(85,5 \%)$ revelou não frequentar, actualmente, qualquer modalidade de educação ou formação, sendo que:

i. 346 indivíduos responderam que, actualmente, não se encontram a estudar, mas pensam vir a estudar (44,1\%);

ii. 325 indivíduos responderam que, actualmente, não se encontram a estudar e nem pensam vir a estudar $(41,4 \%)$, explicitando essa decisão com base em diversas razões. Estas foram organizadas por categorias, conforme se observa na tabela que se segue;

b) Apenas 75 indivíduos $(9,5 \%)$ se encontravam a estudar, no momento da aplicação do questionário.

\subsection{Caracterização do Processo de RVCC concretizado pelos inquiridos}

Neste sub-ponto abordar-se-á as formas de conhecimento do Processo de RVCC, as razões que conduziram os adultos ao mesmo, as dificuldades e os apoios identificados durante o Processo de RVCC. 


\subsubsection{Formas de conhecimento do Processo de RVCC}

Observemos a Figura 5:

Figura 5 - Formas de conhecimento do Processo de RVCC (totalidade dos inquiridos)

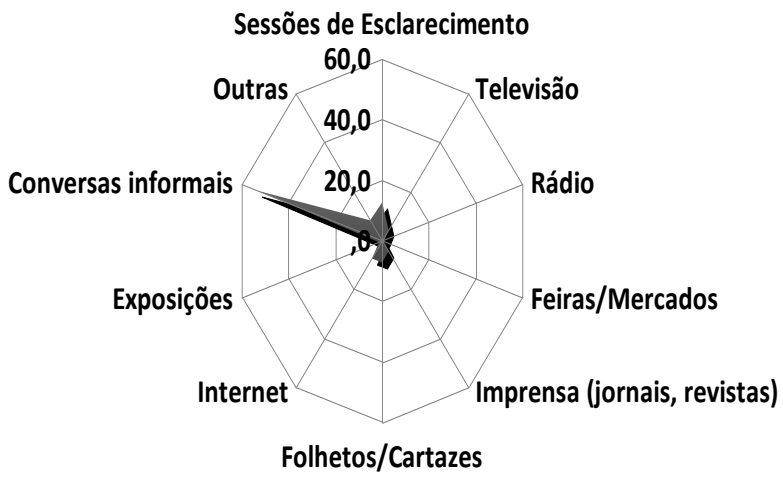

Fonte: Inquérito por Questionário das Novas Qualificações, 2013

Como se pode verificar, das diversas formas de conhecimento, aquela que reuniu um maior número de escolhas foi o item "conversas informais" com amigos, familiares e conhecidos (55,1\%). O "passa palavra" parece ter assumido um papel fundamental na divulgação do trabalho dos CRVCC, em concreto do Processo de RVCC aí concretizado. Este facto evidencia que o papel dos próprios indivíduos, na divulgação do processo, parece ter sido mais eficaz do que a acção das instituições.

No início de funcionamento dos Centros de RVCC, a divulgação da actividade do Centro, envolvendo os meios de comunicação social (rádio e televisão) e Internet era, ainda, pouco significativa, com algum relevo apenas na imprensa regional, tal como nos indicam as respostas dos inquiridos. De referir, ainda, a referência dada às "sessões de esclarecimento", que foram um dos principais meios de divulgação organizados e concretizados pelos próprios CRVCC.

\subsubsection{Razões que conduziram ao Processo de RVCC}

De igual modo, procurou conhecer-se, junto dos adultos certificados entre 2000 e 2005, as razões que os levaram a inscreverem-se num Centro de RVCC.

Figura 6 - Razões possíveis para frequentar o Processo de RVCC (totalidade dos inquiridos) 


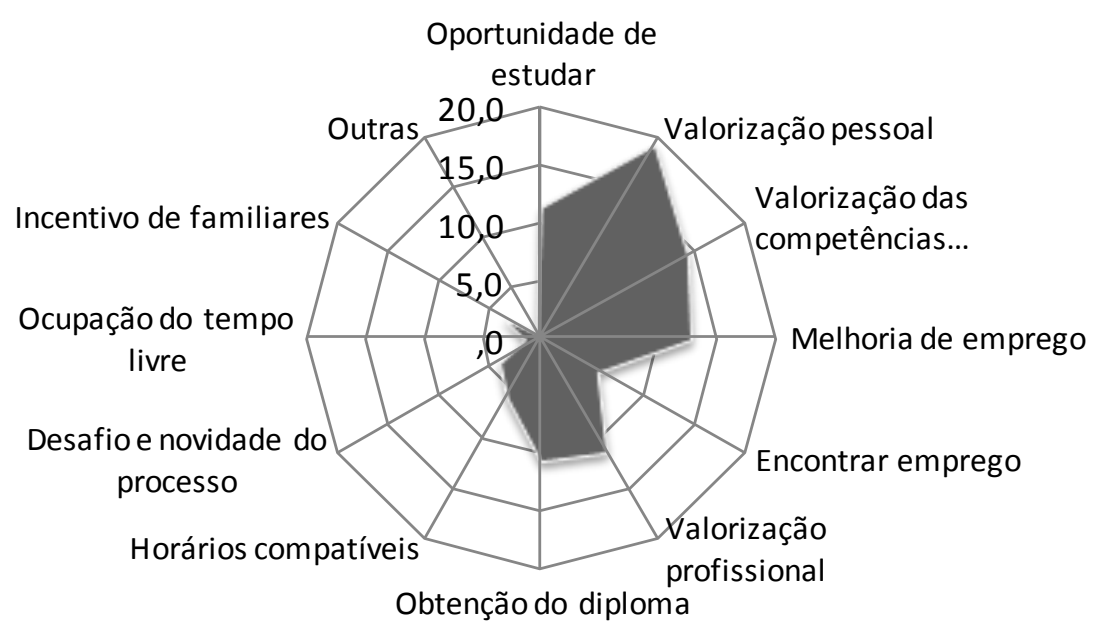

Fonte: Inquérito por Questionário das Novas Qualificações, 2013

Pode, em síntese, concluir-se o seguinte:

- As razões associadas ao desenvolvimento pessoal $(42,6 \%)$ prevaleceram sobre o desenvolvimento profissional $(29,4 \%)$, que surge num plano secundário.

- Os adultos, na procura do Centro de RVCC, valorizaram a oportunidade que the foi aberta pelo Processo de RVCC $(27,4 \%)$, bem como os horários compatíveis.

- Os adultos não procuraram o Centro de RVCC apenas para Ocupar o seu tempo livre, pois este item foi o menos escolhido $(1,3 \%)$.

A análise estatística complementar - entretanto realizada, com base nos testes referidos anteriormente referidos - revelou que: (i) o item Desafio e novidade do processo foi mais valorizado pelos indivíduos mais velhos; (ii) a Possibilidade de Encontrar Emprego foi um item mais valorizado pelos indivíduos mais novos; (iii) a Possibilidade de Encontrar Emprego foi um item mais valorizado pelos indivíduos desempregados.

\subsubsection{Dificuldades identificadas durante o Processo de RVCC}

No que respeita às dificuldades sentidas durante a concretização do Processo de RVCC, a distribuição das respostas obtidas encontra-se na figura seguinte:

Figura 7 - Dificuldades sentidas durante o processo de RVCC (totalidade dos inquiridos) 


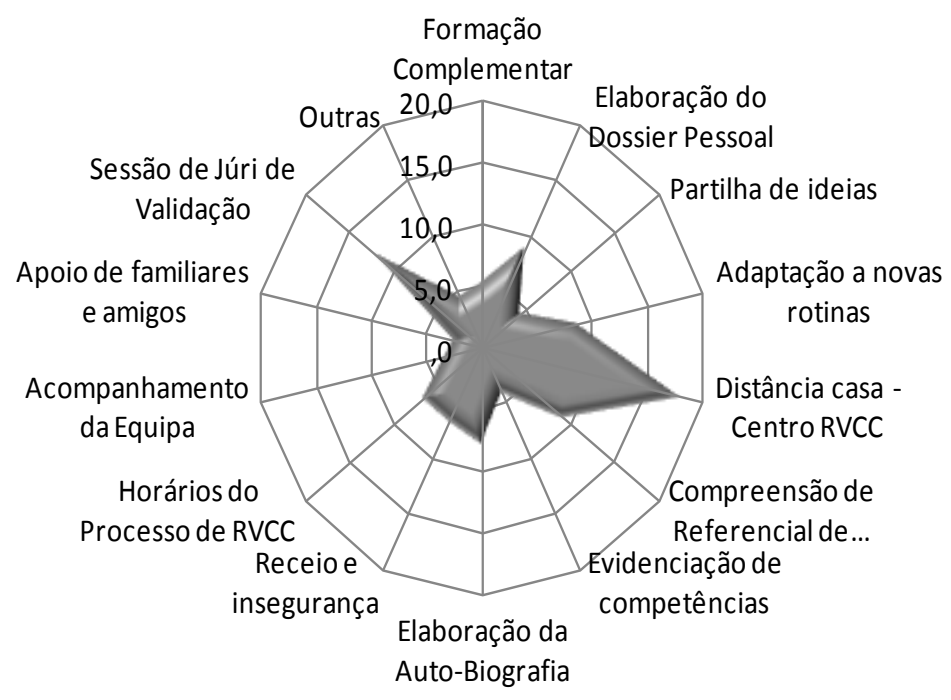

Fonte: Inquérito por Questionário das Novas Qualificações, 2013

Da observação da figura anterior, pode referir-se o seguinte:

- As dificuldades mais frequentemente sentidas, durante o Processo de RVCC, foram a Distância Casa-Centro RVCC (17,8\%) e a Sessão de Júri de Validação $(11,8 \%)$;

- Onde foram referidas menos frequentemente dificuldades foi no Acompanhamento da equipa (3,3\%) e no Apoio de familiares e amigos $(2,5 \%)$.

\subsubsection{Apoios recebidos durante o Processo de RVCC}

O apoio disponibilizado durante o Processo, por parte dos Centros de RVCC, foi outra das questões colocadas.

As respostas foram agrupadas em 5 categorias, conforme consta na tabela seguinte: (1) Equipa Pedagógica (2) Componente logística/organizacional, (3) Formação, (4) Material e Equipamento, (5) Outras, conforme se apresenta na Tabela 6.

Tabela 6- Processo de RVCC: Apoios do Centro de RVCC (todos os inquiridos)

\begin{tabular}{|l|c|c|c|}
\hline \multicolumn{2}{|c|}{ Apoios } & $\begin{array}{c}\text { Frequência } \\
\text { Absoluta } \\
\text { (n) }\end{array}$ & $\begin{array}{c}\text { Frequência } \\
\text { Relativa } \\
\text { (\%) }\end{array}$ \\
\hline Equipa pedagógica & Disponibilidade da equipa & 317 & 19,7 \\
\hline
\end{tabular}




\begin{tabular}{|c|c|c|c|}
\hline & $\begin{array}{c}\text { Relação de proximidade com } \\
\text { a equipa }\end{array}$ & 217 & 13,5 \\
\hline & Incentivo da equipa & 212 & 13,1 \\
\hline & Subtotais & 746 & 46,3 \\
\hline \multirow{5}{*}{$\begin{array}{l}\text { Componente } \\
\text { logística/ } \\
\text { organizacional }\end{array}$} & Flexibilidade de horários & 153 & 9,5 \\
\hline & Instalações do Centro RVCC & 98 & 6,1 \\
\hline & Itinerância & 79 & 4,9 \\
\hline & Apoio no transporte & 31 & 1,9 \\
\hline & Subtotais & 361 & 22,4 \\
\hline \multirow{3}{*}{ Formação } & $\begin{array}{l}\text { Ajuda na construção do } \\
\text { Dossier Pessoal }\end{array}$ & 193 & 12 \\
\hline & Formação complementar & 95 & 5,9 \\
\hline & Subtotais & 288 & 17,9 \\
\hline \multirow{3}{*}{$\begin{array}{c}\text { Material e } \\
\text { Equipamento }\end{array}$} & Equipamento informático & 120 & 7,5 \\
\hline & $\begin{array}{l}\text { Material didáctico } \\
\text { disponibilizado }\end{array}$ & 86 & 5,3 \\
\hline & Subtotais & 206 & 12,8 \\
\hline \multirow[t]{3}{*}{ Outras } & Outras & 10 & 0,6 \\
\hline & Subtotais & 10 & 0,6 \\
\hline & Totais & 1611 & 100,0 \\
\hline
\end{tabular}

Fonte: Inquérito por Questionário das Novas Qualificações, 2013

No que respeita aos principais apoios disponibilizados pelo Centro RVCC, verificou-se que:

a) A equipa pedagógica do Centro de RVCC - a sua Disponibilidade (19,7\%), Relação de proximidade $(13,5 \%)$ e incentivo $(13,1 \%)$ - foi o principal apoio evidenciado pelos adultos, reunindo $46,3 \%$ do total de respostas expressas pelos indivíduos, o que nos leva a afirmar que a relação pedagógica (e, certamente, pessoal) da equipa com os adultos, constituiu-se como um apoio fundamental no âmbito do Processo de RVCC;

b) Em segundo lugar, surge a categoria componente logística/organizacional, com um total de $22,4 \%$ das respostas dos inquiridos, onde se destacam os itens Flexibilidade de horários e o funcionamento em regime de itinerância. Estes factores terão potenciado a proximidade dos adultos com os processos de qualificação e de aprendizagem; 
c) Em terceiro lugar, surgem os apoios relacionados com a formação, no âmbito do processo, nomeadamente os itens Ajuda na construção do Dossier Pessoal e a superação de dificuldades, através das horas de Formação complementar, que reuniram 17,9\% do total de respostas expressas pelos inquiridos;

d) O apoio menos referido pelos adultos que frequentaram o Processo de RVCC foi o transporte (1,9\%), o que se deve ao facto de os Centros, à data, também funcionarem em regime de itinerância, deslocando os seus profissionais aos locais de residência dos adultos;

e) A partir dos dados constantes do quadro anterior, infere-se que os apoios relacionados com a dimensão humana foram importantes no acompanhamento dos adultos em Processo de RVCC, em contrapartida com uma dimensão logística/material, que não se revelou tão importante para os inquiridos.

\subsection{Avaliação de alguns dos impactos do Processo de RVCC nos adultos certificados}

\subsubsection{Dimensão Profissional}

1. No início do processo de RVCC, $82,0 \%$ dos inquiridos estava empregada (644 indivíduos) e 15,4\% desempregada (121 indivíduos). Não responderam a esta questão 20 inquiridos (2,5\%).

2. A análise estatística complementar - entretanto realizada, com base nos testes referidos anteriormente referidos - revelou que: a taxa de emprego é maior nos homens $(90,5 \%)$ do que nas mulheres $(79,5 \%)$.

3. Dos 644 empregados, $74,2 \%$ dos indivíduos (478) não mudou de actividade profissional. Todavia, essa foi uma realidade para 25,8\% dos indivíduos (166).

4. Em $69,9 \%$ dos adultos empregados que viveu alteração profissional, tal aconteceu 1 ano após a conclusão do Processos de RVCC.

5. Relativamente à natureza da alteração da situação profissional: a maioria dos inquiridos experimentou alterações ao nível da mudança de profissão; 16,2\% mudou de remuneração e $15,7 \%$ mudou de local de trabalho. 
6. A maioria (53\%) dos indivíduos empregados que experimentou mudança da sua actividade profissional considerou que o Processo de RVCC influenciou ou influenciou muito essa mudança $(43,4 \%$ dos indivíduos considerou mesmo que o Processo de RVCC influenciou muito a mudança de actividade profissional).

7. Após o Processo de RVCC, a maioria dos desempregados (55,4\% dos indivíduos, o que corresponde a 67 adultos), encontrou emprego; daqueles 67 adultos, 31,3\% encontrou emprego, entre 1 a 3 anos após o Processo de RVCC (25 adultos), sendo de salientar que $20,9 \%$ dos que encontraram emprego, estando desempregados, conseguiram-no ate 1 anos após o Processo de RVCC (14 adultos).

8. Quanto à influência do processo de RVCC na alteração da situação profissional, nos indivíduos que se encontravam desempregados, 40,2\% considerou que 0 Processo de RVCC influenciou ou influenciou muito o facto de ter conseguido um emprego (31,3\% dos indivíduos considerou mesmo que o Processo de RVCC influenciou muito).

\subsubsection{Dimensão Aprendizagem ao Longo da Vida}

1. Não se registaram diferenças ao nível da participação em actividades de aprendizagem, antes e depois do Processo de RVCC (Figura 8).

Figura 8 - Participação em actividades de aprendizagem (todos os inquiridos)

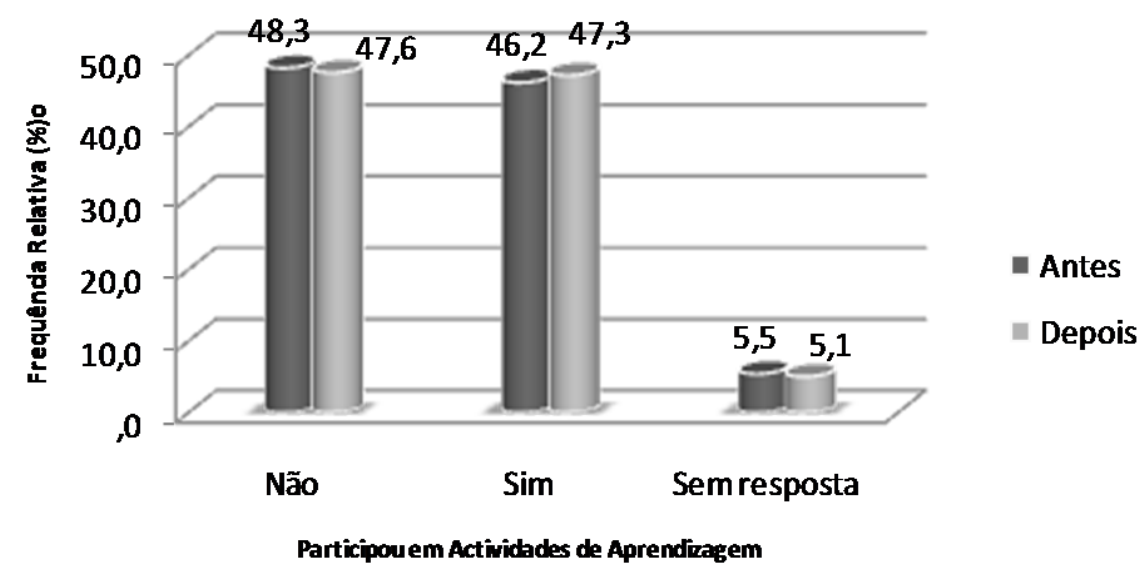


2. As actividades de aprendizagem mais frequentemente protagonizadas pelos inquiridos, antes e depois do Processo de RVCC, relacionaram-se com a formação profissional (tendo aumentado a taxa de frequência), seguindo-se as actividades de aprendizagem na área da informática (tendo diminuído a taxa de frequência).

3. Quantos aos locais onde ocorreram essas actividades de aprendizagem, prevaleceram os contextos formais de qualificação, antes e depois do Processo de RVCC (54,3\% antes e 50,2\% depois). De referir a importância dos contextos não formais de trabalho, nos quais os indivíduos realizaram aprendizagens.

4. A análise estatística complementar - entretanto realizada, com base nos testes referidos anteriormente referidos - revelou que: (i) antes do Processo de RVCC, os indivíduos mais velhos participavam mais em actividades de aprendizagem do que os indivíduos mais novos; (ii) os indivíduos com maior índice de participação em actividades de aprendizagem, antes do Processo de RVCC, exibem, actualmente, maiores níveis de escolarização; (iii) Os indivíduos com maiores níveis de escolaridade participaram mais em actividades de aprendizagem, após o Processo de RVCC.

\subsubsection{Avaliação dos impactos do Processo de RVCC nos adultos certificados (percepção global)}

No que respeita à importância e influência que os adultos atribuíram ao Processo de RVCC (de entre um total de 21 itens, sobre os quais cada adulto se posicionou numa escala tipo Likert, de 1 a 5 valores -em que 1 significa nada importante e 5 muito importante - verificou-se o seguinte:

1. No que respeita à importância e influência que os adultos atribuíram ao Processo de RVCC, foram destacados, como mais importantes, por ordem decrescente, os seguintes itens (cf. tabela seguinte):

a. "Valorização das minhas competências e conhecimentos pessoais" (média de 4,25); 

b. "Conhecimento das minhas capacidades" (média de 4,12);
c. "Aumento da confiança em mim próprio (média de 4,05).

2. Como menos importantes, foram referidos os seguintes itens:
a. "Capacidade de ajuda nas tarefas escolares dos filhos (média de 3,07);
b. "Participação em actividades realizadas na minha comunidade (média de $2,85)$;
c. "a intervenção cívica em associações, clubes..." (média de 2,83).

Observemos, agora, a Tabela 7:

Tabela 7 - Importância atribuída ao processo de RVCC em diferentes dimensões (médias)

\begin{tabular}{|l|c|}
\hline Dimensões Consideradas & Média \\
\hline Pessoal & $\mathbf{3 , 9}$ \\
\hline Aprendizagem & 3,6 \\
\hline Familiar & 3,4 \\
\hline Profissional & 3,3 \\
\hline Social & 3 \\
\hline
\end{tabular}

Fonte: Inquérito por Questionário das Novas Qualificações, 2013

Da leitura da informação anterior, pode inferir-se que:

1.0 Processo de RVCC foi avaliado positivamente em todas as dimensões consideradas, sendo a dimensão pessoal a mais valorizada e a dimensão social a menos valorizada;

2. O aspecto mais frequentemente valorizado prende-se com o conhecimento e as competências das pessoas: conhecer as suas próprias competências, ter consciência do que se sabe e ter a oportunidade de valorizar tudo isso foram vectores muito valorizados pelos inquiridos;

3. É relevante o facto da dimensão social ser a menos valorizada, particularmente os itens relativos à participação e intervenção cívica. 
Em jeito de conclusão, podemos afirmar que a principal causa que determinou a decisão conducente à frequência do Processo de RVCC, foi de dimensão pessoal e não a profissional. A dimensão pessoal foi o centro de gravidade do Processo de RVCC para as pessoas que o concluíram. É de relevar a significativa participação em actividades de aprendizagem de natureza profissional.

\section{Referências Bibliográficas}

ALONSO, L., IMAGINÁRIO L., MAGALHÃES, J. et al (2001). Referencial de Competências-Chave - Educação e Formação de Adultos. Lisboa: Agência Nacional de Educação e Formação de Adultos.

ESDIME (2007). Estudo sobre o Impacto da Certificação de Competências na Vida das Pessoas: A Experiência da Esdime. Camarate: IEFP.

GHIGLIONE, R. \& MATALON, B. (1992). O Inquérito: Teoria e Prática. Oeiras: Celta Editora.

HILL, M. \& HILL, A. (2005). Investigação por Questionário. Lisboa: Edições Sílabo.

LEINHARDT, G. \& LEINHARDT, S. (1990). “Exploratory Data Analysis". in John P. Reeves (Ed). Educational Research, Methodology, and Measurement - a International Handbook. Oxford: Pergamon Press.

NICO, B. (coord.), NICO, L., FERREIRA, F. \& TOBIAS, A. (2013). Educação e Formação de Adultos no Alentejo. O Processo de Reconhecimento, Validação e Certificação de Competências no período 2000-2005. Mangualde: Edições Pedago.

NICO, L. (2009). Avaliação do(s) Impacto(s) do Processo de Reconhecimento, Validação e Certificação de Competências, no Alentejo (período 2001-2005). [Tese apresentada à Universidade de Évora, tendo em vista a obtenção do Grau de Doutor em Ciências da Educação]. Évora: Universidade de Évora. (policopiada)

PEREIRA, A. (2008). SPSS Guia Prático de Utilização. Análise de dados para Ciências Sociais e Psicologia. Lisboa: Edições Sílabo.

PUNCH, K. (1998). Introduction to Social Research - Quantitative \& Qualitative Approaches. London: SAGE Publication.

REIS, E., VICENTE, P. \& FERRÃO, F. (2001). Sondagens - $A$ amostragem como factor decisivo de qualidade. Lisboa: Edições Sílabo. 
RICO, H. \& LIBÓRIO, T. (2009). Impacte do Centro de RVCC da Fundação Alentejo na qualificação dos alentejanos. Évora: Fundação Alentejo.

SOUSA, A. (2005). Investigação em Educação. Lisboa: Livros Horizonte.

VERDASCA, J. (2002). Desempenho Escolar, Dinâmicas de Evolução e Elementos Configuracionais Estruturantes: os casos do 2. e 3. o Ciclos do Ensino Básico nos municípios de Évora e de Portel [Tese apresentada à Universidade de Évora tendo em vista a obtenção do Grau de Doutor em Ciências da Educação].

\section{Legislação referida}

\begin{tabular}{ll}
\hline & $\begin{array}{l}\text { Cria uma Rede Nacional de Centros de } \\
\text { Reconhecimento, Validação e Certificação de } \\
\text { Competências (Centros RVCC), a partir da qual se } \\
\text { promove o Sistema de Reconhecimento, Validação e } \\
\text { Portaria n.o 1082-A/2001, de 5 de } \\
\text { Setembro } \\
\text { do processo de acreditação das entidades promotoras } \\
\text { dos Centros. }\end{array}$ \\
\hline Portaria no 370/2008, de 21 de Maio & $\begin{array}{l}\text { Regula a criação e o funcionamento dos Centros Novas } \\
\text { Oportunidades. }\end{array}$ \\
\hline Portaria n.o 135-A/2013, de 28 de & $\begin{array}{l}\text { Regula a criação e o regime de organização e } \\
\text { funcionamento dos Centros para a Qualificação e o } \\
\text { Maio }\end{array}$ \\
\hline
\end{tabular}

\section{Sítio de internet consultado}

www.novasoportunidades.gov.pt (consultado em Junho 2010). 